exposure of the whole numbers of the calibration series.

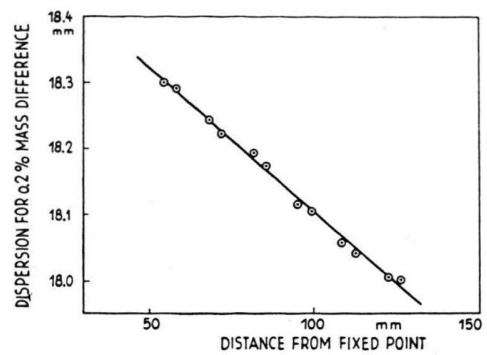

Fig. 8. Dispersion curve for $0.2 \%$ mass difference.

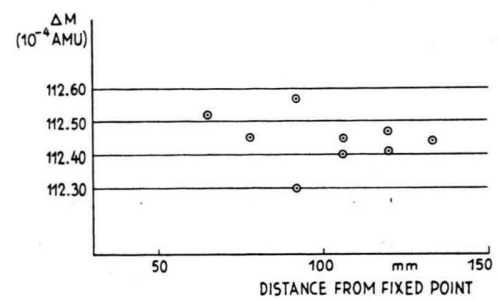

Fig. 9. Mass differences of $\mathrm{N}_{2}{ }^{14}-\mathrm{C}^{12} \mathrm{O}^{16}$ doublet on the various positions of photographic plate.

The mass difference of $\mathrm{N}_{2}{ }^{14}-\mathrm{C}^{12} \mathrm{O}^{16}$ doublet is determined preliminarily by the above mentioned calibration method. Fig. 9 shows the reliability of the measurement under the present condition of the new apparatus. The simple arithmetical mean of
$\mathrm{N}_{2}{ }^{14}-\mathrm{C}^{12} \mathrm{O}^{16}$ doublet mass difference so obtained is $112.441 \pm 0.019\left(10^{-4} \mathrm{amu}\right)$, where the error quoted indicates the probable error.

\section{Conclusion}

The dispersion of the newly constructed large mass spectrograph is satisfactory but the exact double focusing point has not yet been found. Sometimes the focus planes, directional and velocity, are observed to shift slightly due to unexpected causes. The investigation of the cause is now being carried on.

The calibration method used here may be checked by comparing it with the ordinary calibration method, for example, using hydrocarbon fragments in high mass range, say mass 200 or 300 .

The authors wish to express their thanks to Prof. J. $\mathrm{Mat}$ a u ch and Dr. E. Everling for their kind information on the magnetic exciting current stabilizer, to Dr. R. H e r zog for his kind information on the magnetic stray field shielding, to Prof. J. M a t $\mathrm{t} \mathrm{a} \mathrm{uch}$ and Prof. S. $\mathrm{Kikuchi}$ for their encouragement, to Profs. K. Hu $\mathrm{sh}$ i mi, T. Nagamiy a and other members of the Faculty for their financial support, to Prof. T. A s a d a for his continuous interest in their mass determination work, to Mr. S. M a t sumoto and Mr. T. Nak at suk a for their kind assistances, and to Dr. and Mrs. Nishiwaki for their very kind suggestion on the languages.

\title{
The ion source of the Amsterdam Isotope Separator
}

\author{
J. Kistemaker, P. K. Rol, J. Schutten and C. de Vries \\ Laboratorium voor Massaspectrografie, Stichting F.O.M., Hoogte Kadijk 202, Amsterdam. C. \\ (Z. Naturforschg. 10 a, 850-856 [1955]; eingegangen am 26. Juli 1955) \\ To J. Mat ta uch for his $60^{\text {th }}$ birthday
}

The ion source has as essential parts:

1. the discharge chamber with filament,

2. the furnace for the production of the gas (vapour),

3. the heated screens and the labyrinths,

4. the acceleration- and lens electrode,

5. the power supplies and cooling systems,

6. the arc stabilization.

These parts are shown and explained. Especially a survey has been given of the five types of breakdown which can disturb a smooth ion production.

\section{$\S 1$. The discharge chamber with filament}

$\prod$ he ion source required for the separator is an arc source ${ }^{1,2,3}$. Electrons originating from the filament are accelerated through one or two hundred

1 C. J. Zilversch o o n, An Electromagnetic Isotope Separator, Thesis University Amsterdam, 1954.

2 L. O. L o ve and W. A. B e 11 , U.S.A.E.C., A.E.C.D. $3502,1950$. volts and ionize the gas molecules with which they collide. For the following explanation see fig 1 .

We had to construct the source block (1) from a material that should resist chemical reaction with various substances, even at high temperatures. There-

${ }^{3}$ R.H. V. M. D awton and M. L. Smit, Quarterly Rev. IX, 1 [1955]. 

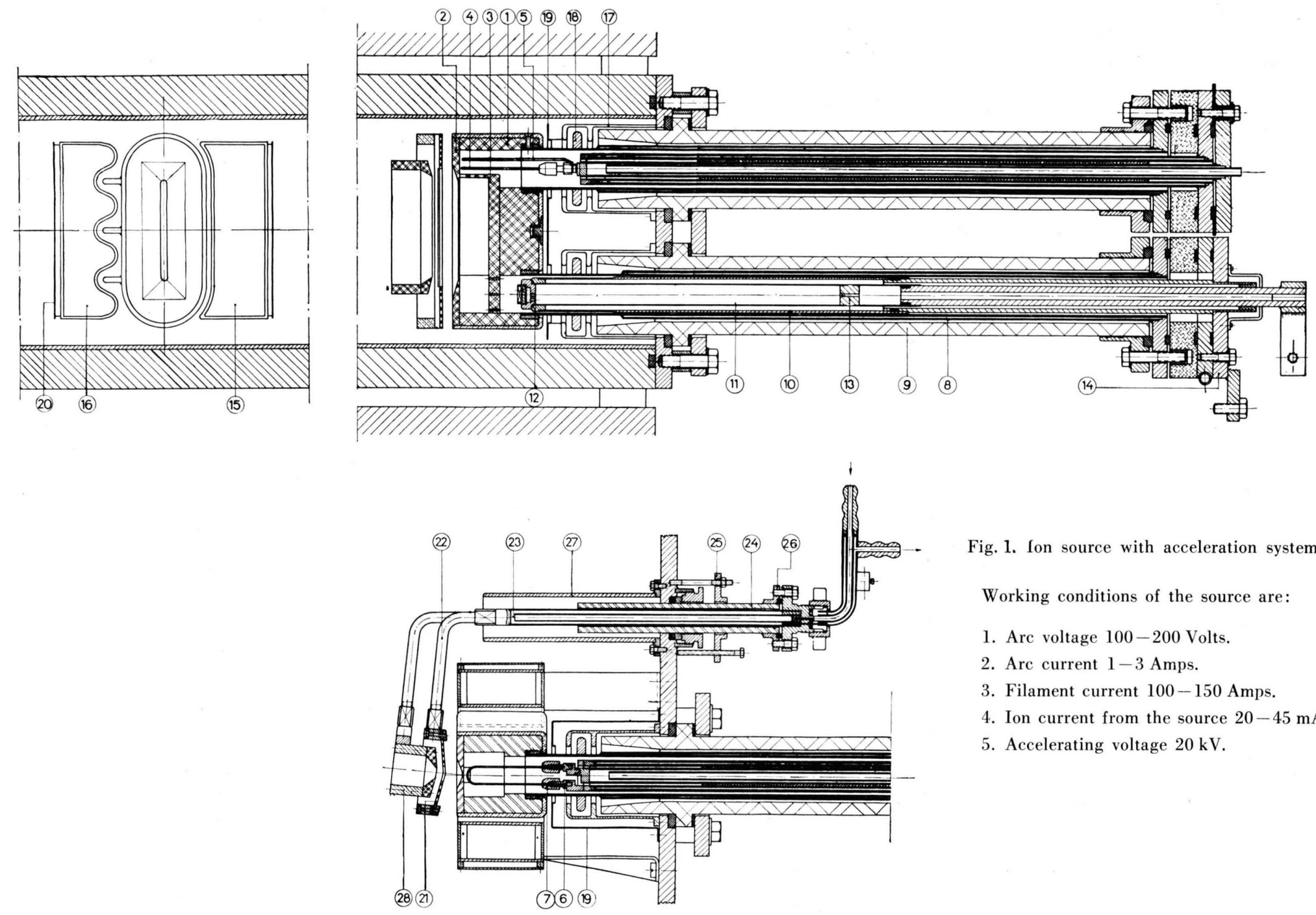

Fig. 1. Ion source with acceleration system.

Working conditions of the source are

1. Arc voltage $100-200$ Volts.

2. Arc current $1-3$ Amps.

3. Filament current 100-150 Amps.

4. Ion current from the source $20-45 \mathrm{~mA}$.

5. Accelerating voltage $20 \mathrm{kV}$. 
fore the source is machined out of graphite and has a stainless steel envelope. The graphite front plate (2) in which the exitslit of the source is made, is removable, so that different shapes and sizes of slits can easily be applied. Moreover it enables an easy cleaning of the source which cleaning is further facilitated by the application of a separate graphite lining (3). On the side of the furnace this lining is provided with holes to admit the vapour and on the filament side with a collimating slot, through which the primary electrons enter the discharge chamber. The electrons are prevented from going directly to the walls by the axial magnetic field. A molybdenum reflector plate (5) at the filament potential prevents the electrons from going directly to the top of the anode house. With different types of linings in the ion source we found that we should admit the gas or vapour homogenous over the whole length of the arc chamber, especially when we used a long arc chamber with a small cross section.

In the source being in use at the moment, the gas is admitted diffuse through many little holes, in an arc chamber with a large cross section. When the gas is not admitted diffuse, the plasma cap is nearer to the slit at the place, where the gas pressure is highest. In that case the ion beam leaving the source is not perpendicular to the exit slit and one gets great losses of ions to the pole pieces. When we use a collimating slot with rectangular dimensions, and open to the front plate, sometimes the image at the collector is double. Probably this is because of the penetration of the accelerating field through the exitslit. This penetration splits up the discharge in two parts at both sides of the slit. It is obvious that these two discharge columns act as two objects and apparently can give two images at the collector. We solved this problem more or less by giving the collimating slot a curved form, following the potential lines of the penetrating field. However, the life time of the filament was reduced because we had to bend it in a special form, like the collimating slit.

The filament (4) is made of $2 \mathrm{~mm}$ tungsten wire. The connections of the filament consist of a conical beryllium-copper holder (6) with incisions and a stainless steel nut (7), which combination prevents troubles caused by thermal dilatation.

\section{$\S 2$. The furnace for the production of the vapour}

(see fig. 2)

The difficulty in our case was that we had so little space available for the furnace. The only place was the lower supporting tube (8) of the source inside the insulator (9). The inside diameter of this stainless steel supporting tube is $29 \mathrm{~mm}$. It is double-walled and water cooled. We solved this furnace problem in the following way.

The furnace is constructed from two concentric stainless steel tubes (10) and (11). A ring (12) has been welded at the end between the inner- and outertube and at $250 \mathrm{~mm}$ from the end a stainless steel stop (13) has been welded in the innertube. The thickness of the wall of the innertube and the formost part of the outertube is $0,75 \mathrm{~mm}$. The stainless steel tubes are silver soldered to two thick-walled copper tubes from which the outer one has been soldered on a flange (14). Thick copper strips are the electrical leads.

A current up to 400 Ampères flows through the

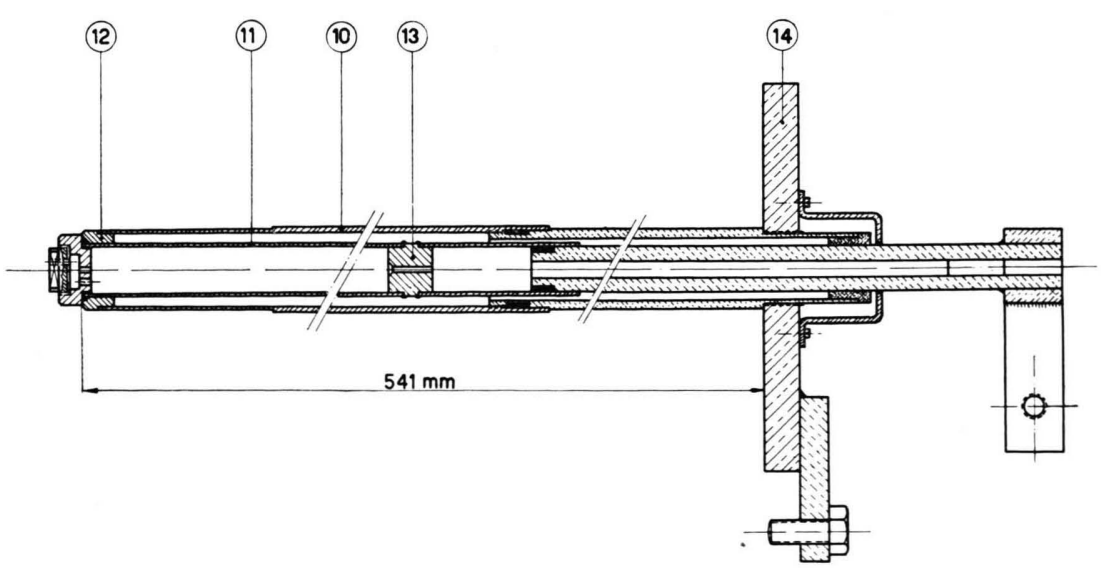

Fig. 2. Evaporation furnace of the Amsterdam isotope separator. 
tubes and the thin walls are heated to about $800{ }^{\circ} \mathrm{C}$. The inner one is filled with the solid material which we want to separate.

To prevent solid material to be blown into the ion source, by small gas explosions during the pumping or the heating up of the furnace, a special cover has been made. This cover is hollow and has at both sides four holes with a diameter of $2 \mathrm{~mm}$. The holes are made in such a way that the cover acts as a lock. This lock was very essential.

The temperature is measured with a thermocouple which has been welded in the stop (13) inside the furnace. The flange (14) is water-cooled.

\section{§. The heated screens and the labyrinths}

A serious problem is formed by high-tension discharges and breakdowns which may easily occur in the vicinity of the source. We had to face no less than five types of discharges.

\section{a. Cold (Townsend) discharges}

Since the pressure inside the vacuum chamber is low, we can obviate this type of discharge by enclosing the ion source in an earthed screening cap at a small distance from the ion source. We are at the left side of the Paschen minimum and therefore we must make p.d. as low as possible.

\section{b. Discharges due to field emission}

The spacing between the ion source and the screening cap must not be taken too small, for field emission can arise at electric field strenghts of a few hundred $\mathrm{kV}$ per $\mathrm{cm}$. We found that $4 \mathrm{~mm}$ was a reasonable value. Furthermore, sharp edges and points are avoided and the surfaces of the electrodes and caps are highly polished.

\section{c. P.I. G. discharges}

In the vicinity of the source the shape of the electric and magnetic fields is so that P.I.G. discharges can occur. The pole pieces are negative with respect to the ion source. Thus a component of the electric field is parallel to the magnetic field. Obviously these discharges can also be suppressed by the earthed screening caps around the source (15 and 16).

\section{d. Trochoidal discharges}

Trochoidal discharges can occur wherever the electric field $E$ is perpendicular to the magnetic field $B$. In that case charged particles tend to move in a trochoidal trajectory perpendicular to $E$ and $B$. Electrons with zero initial velocity describe a cycloidal path and the radius of the rolling circle is given by

$$
\varrho=m E / e B^{2} .
$$

When the distance between the ion source and the screening caps is larger than $2 \varrho$, electrons will pass unhampered between them and

a. reach the porcelain insulator where they cause instabilities and give rise to breakdowns (melting);

b. give electron multiplication and the drain of electrons on the positive source absorbs large amounts of electrical energy, producing excessive heating and in serious instances destroys metallic surfaces.

We can intercept the electrons by making the distance $d$ between source and cap

$$
d<2 \varrho .
$$

Since $E=V / d$ and the main circle of the separator has a radius

$$
r=(1 / B) \cdot \sqrt{2 M V / e},
$$

we must fulfill the following condition

$$
d<r \sqrt{m / M} .
$$

Substituting $r=1020 \mathrm{~mm}$ and taking the most unfavourable case (uranium separation) we find $d<1,5 \mathrm{~mm}$. Because this is an impracticably small distance, we have solved the problem in another way ${ }^{4}$. We have maintained a distance of $4 \mathrm{~mm}$, but we use an undulating cap (16) and protrusions on the source as shown in the front view of the source. In this way an electric field component in the direction of the magnetic field is introduced which pulls away the electrons to the positive body of the source. The configuration mentioned is only applied on one side of the source since all electrons emerging from the beam go that way. The cap on the other side is a plain one (15).

e. Creep discharges

To prevent these discharges we had to make the distance between the high potential parts and earthed

$$
{ }^{4} \text { S. E. R a u c h, J. Appl. Phys. 22, } 1128 \text { [1951]. }
$$


parts over the insulators as long as possible. Measures hat to be taken to obviate the deposition of metal vapours on the insulators. The porcelain high tension insulators are protected by a system of caps (17) and (19) and rings (18) shaped like a labyrinth and acting as baffles.

When solid charge materials are used it is of importance that the discharge chamber of the source is at a higher temperature than the furnace, in order to avoid sublimation in the source, for this can give instabilities in the arc, which in turn cause much hash. When the source is $700{ }^{\circ} \mathrm{C}$ the radiation loss can amount up to $2000 \mathrm{~W}$ atts. The total power input of the source may sometimes be of that order, but can also be considerably less. Therefore the source is externally heated. Both screening caps are designed as stainless steel boxes in which electric heater elements are constructed. The element is a kanthal strip of $40 \times 0,3 \times 200 \mathrm{~mm}^{3}$ and the current through this strip is 200 Ampères. The heating input of the caps is $1000 \mathrm{~W}$ atts each.

Radiation shields (20) are fitted to reduce the loss of heat on the "wrong side".

\section{§ 4. The acceleration- and lenselectrode}

The figure 1 shows the construction of the acceleration system. The lens electrode (21) consists of two thin graphite plates, mounted on a copper frame. It is supported by a stainless steel tube (22), which in turn is screwed into the water cooled copper holder (23). This holder is mounted on a porcelain insulator (24) through which it enters the vacuumchamber. The insulator is vacuumsealed by means of a Wilson seal, which enables an adjustment, with four screws, of the distance between source and electrode. The adjustment flange (25) and the mounting flange (26) for the copper holder are fixed on the porcelain tube with araldite.

A cap (27) protects the insulator from deposits. The earthed electrode (28) is wholly made of graphite. It is supported in a similar way as the lens electrode.

Various slit dimensions and electrode distances were tried. The height of the slit of the lenselectrode was found to be very critical to get a parallel beam in the axial direction. The types shown in the figure are used now and give rather good results.

The data are:

ion exit slit $4 \times 80 \mathrm{~mm}^{2}$, slit in lenselectrode $10 \times 95 \mathrm{~mm}^{2}$, slit in earthed electrode $10 \times 80 \mathrm{~mm}^{2}$, distance between source and lenselectrode $15 \mathrm{~mm}$, distance between lens and earthed-electrode $5 \mathrm{~mm}$. The source was at $+20 \mathrm{kV}$, the lenselectrode at -5 to $-10 \mathrm{kV}$.

The electrodes are heated by heatradiation from the source and ion bombardement. Because of the low heat transfer through the stainless steel supports they can reach a temperature of several hundreds of dregrees centigrade. This is advantageous since it reduces the amount of inlet material depositing on them. The effect of the negative lens voltage on the collectorcurrent and the separating power is different for weak and strong currents. Whereas for weak currents, both are practically independent of the negative high voltage, there is a marked influence at strong currents. By increasing the negative high voltage the ion current from the source remains nearly constant, but the collectorcurrent increases rapidly, especially at the first few $\mathrm{kV}$. This is explained by the reflection of secondary electrons from the beam, thus increasing their space charge compensating action. As a result the loss of ions due to defocussing is appreciably reduced. Changes in the lens action itself are probably not to be neglected, but are up to now not understood, the spacecharge complicating too much. It is certain at any rate that the place of the beamfocus at the collectorside moves when changing the voltage of the negative acceleration electrode (lens electrode).

The influence of the accelerating voltage on the ioncurrent from the source, on the separating power and on the collectorcurrent is shown in fig. 3 .

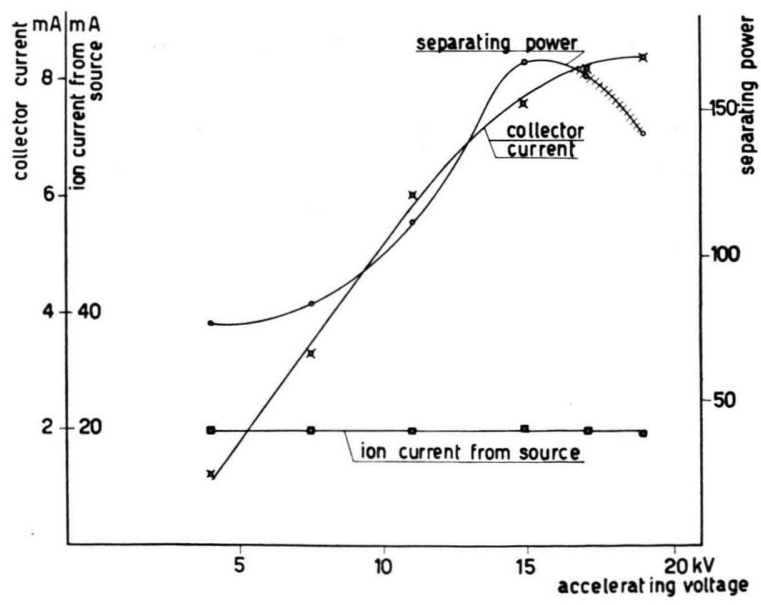

Fig. 3. Effect of the accelerating voltage in case of $\mathrm{Zn}$ vapour in the ion source. The arc was $1 \mathrm{Amp}$. at 50 Volts and the arc pressure was $2 \cdot 10^{-3} \mathrm{~mm} \mathrm{Hg}$ (calculated). 
The influence of the lensvoltage is shown in fig. 4 . We see that the ioncurrent from the source just stays constant, which is an indication that we are working with a "saturated" ioncurrent instead of a "space charge" limited current. Also the occurrence of hash for higher lensvoltage or acceleration voltage points in this direction, the plasma being too weak apparently. The newest information from our friends from Oak Ridge says that we have to work more with the space charge limited case. This brings several implications, however.

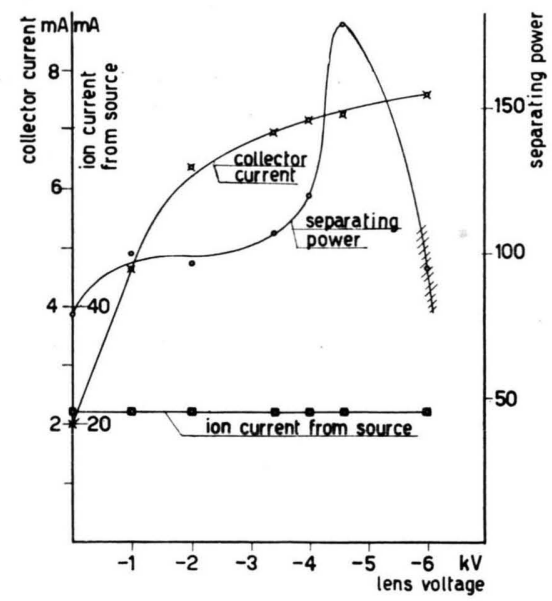

Fig. 4. Action of lensvoltage at strong ioncurrents ( $\mathrm{Zn}$, arc 1 Amp., 50 Volts; arc pressure $2 \cdot 10^{-3} \mathrm{~mm} \mathrm{Hg}$ [calculated] ; accelerating voltage $16 \mathrm{kV}$ ).

\section{$\S 5$. Power supplies and stabilizers}

Since the ion source has a high positive potential with respect to the earthed vacuumchamber $(20-30 \mathrm{kV})$ the electrical power, required for the operation of the source is supplied by a $10 \mathrm{kVA}$, $220 \mathrm{~V} / 220 \mathrm{~V}$ insulating transformer $\mathrm{T}_{1}$ (fig. 5 ) in a delta star connection.

The starpoint of the secundary of this transformer is connected to the corona cap C, surrounding the power supplies, and to the anode of the ion source.

The most important units on high-tension level are:

1. A 3-phase variac $V_{1}$, transformer $T_{2}$ and rectifier unit $\mathrm{RU}_{1}$ for the filament current, in fig. 5 . The 3-phase bridge rectifier delivers $6 \mathrm{~V}$ at $250 \mathrm{~A}$, with a ripple component smaller than $1 \%$ of the D.C. value by inserting $\mathrm{L}_{1}$. An a.c.-supply for the filament would cause continuous vibration in the magnetic field, considerably shortening filament life.

2. A 3-phase variac $\mathrm{V}_{2}$, transformer $\mathrm{T}_{3}$ and rectifier unit $\mathrm{RU}_{2}$ for the arc voltage. This unit provides a voltage of 400 Volts at $10 \mathrm{Amp}$. maximum.

$\mathrm{L}_{2}$ is a filter choke, keeping the ripple component below $1 \%$. In the circuit two series resistors have been inserted; $R_{1}$ serves the electronic stabilization of the arc current (cf. $\S 5.6$ ) and $R_{2}$ limits instabilities in the arc discharge.

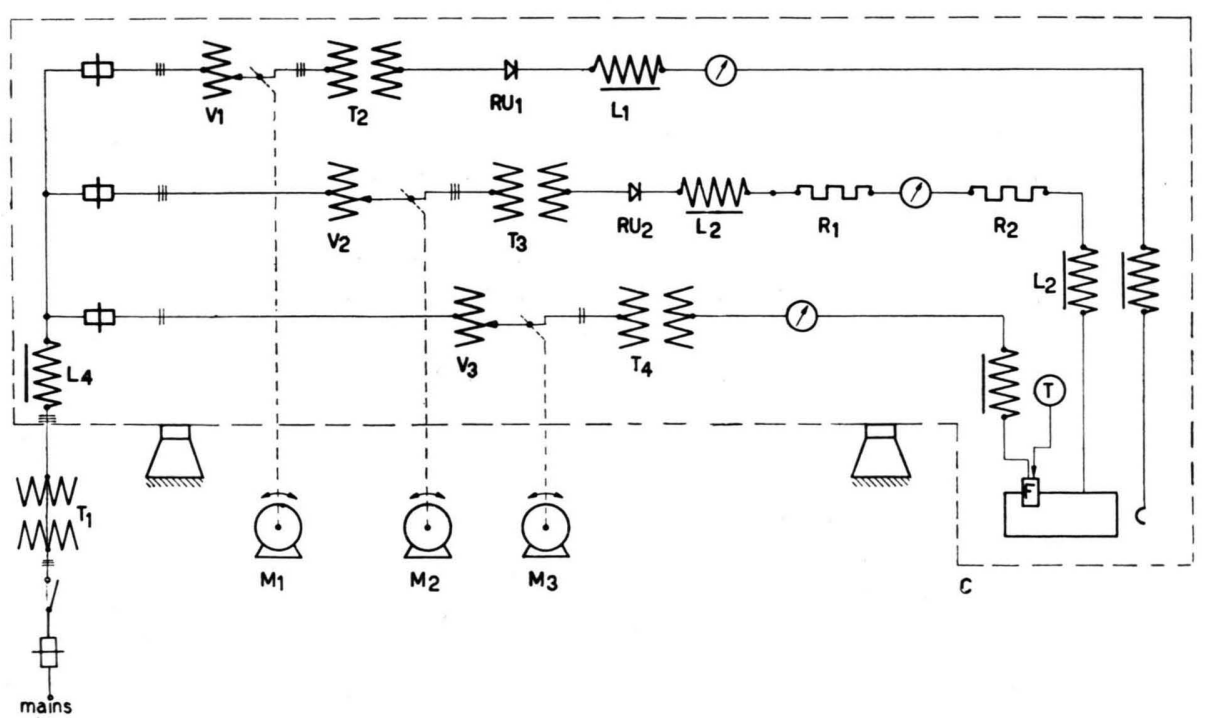

Fig. 5. Simplified diagram of the power supplies for the ion source. 
3. A circulating waterpump for the cooling system of the ionsource, pumping the cooling water around in a closed circuit. The water is, after passage through the ion source, cooled down in an autoradiator, which in turn is cooled by an electric fan.

By means of a waterlock an audible and visible alarm is given when the ion source is switched on with no water flowing.

4. A variac $V_{3}$ and transformer $T_{4}$ for the furnace F. The furnace consists of a stainless steel tube, through which a current of several hundred Amps is flowing, the current being regulated from the control panel by means of push-buttons and a servomotor driving the variac $\mathrm{V}_{3}$.

The temperature is measured by a thermocouple and read on a large $\mathrm{mV}$-meter $\mathrm{T}$, calibrated in degrees centigrade. ends of $\mathrm{P}_{2}$, the voltage between the rotating arm and one of the fixed ends is proportional to the angle $\varphi_{1}$,

$V_{2}=C_{2} \cdot \varphi_{1}$, where $C_{2}$ is another constant, and $V_{2}=C_{1} \cdot C_{2} \cdot V_{1}$.

So the output voltage $V_{2}$ is also proportional to the arc current.

In the compensator the difference is formed between $V_{2}$ and a manually adjustable constant voltage $V_{3}$. This difference voltage is amplified. Exceeding a critical value, the amplified voltage excites a servo-motor $\mathrm{M}_{2}$, driving the variac of the arc voltage unit and thus changing the arc voltage until the desired value has been reached again.

In the equilibrium state $V_{3}$ is proportional to the arc current, so the setting of $V_{3}$ has been calibrated in units arc current.

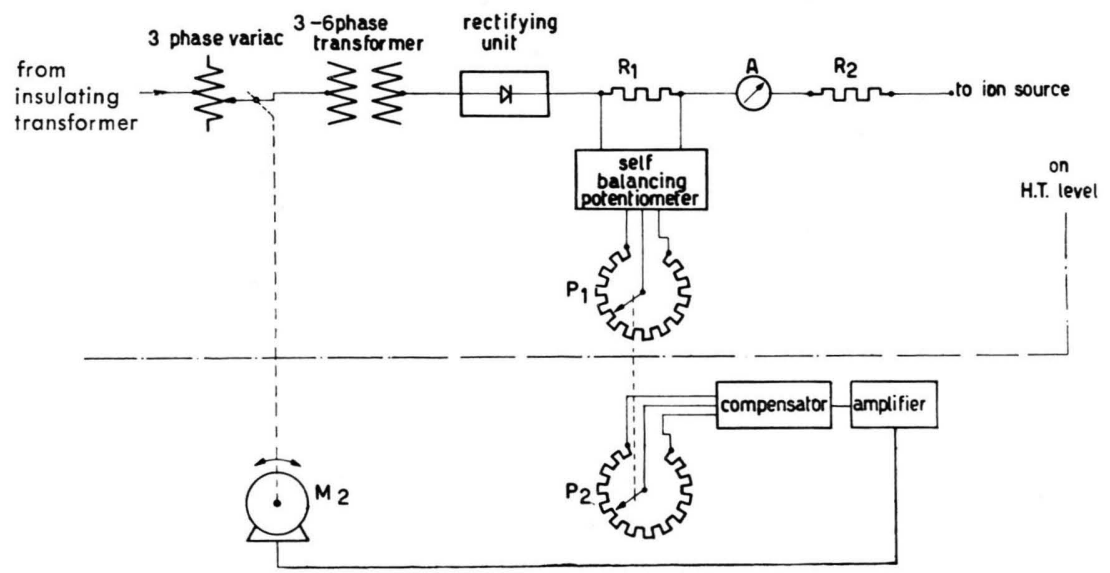

Fig. 6. Functional diagram of the arc current stabilizer.

5. The H.T.-stabilizer has been described in a separate article as a part of the anti-contamination circuit $^{5,6}$.

6. The arc current stabilizer.

In the arc circuit (cf. fig. 6) the voltage drop $V_{1}$ across $\mathrm{R}_{1}$ is converted into an angle displacement $\varphi_{1}$ in the self-balancing potentiometer circuit; so

$$
\varphi_{1}=C_{1} \cdot V_{1} \text {, where } C_{1} \text { is a constant. }
$$

By means of an insulating shaft the rotation angle $\varphi_{1}$ is transmitted to the lowtension-side, where it is coupled to another potentiometer $\mathrm{P}_{2}$.

As a constant voltage is applied to the fixed

5 J. Schutten, C. J. Zilverschoon and J. K is t e m a k e r, Appl. Sci. Res. B 4, 217 [1955].

${ }_{6}^{6}$ J. S c hutte n, Appl. Sci. Res. B 4, 225 [1955].
During a breakdown of the high tension on the ion source, high potentials appear in the most unexpected places. Therefore the ion source has been insulated for radiofrequencies from the corona cap by the h.f. chokes $\mathrm{L}_{3}$, and from the insulating transformer $T_{1}$ by the chokes $L_{4}$. Moreover, in critical places Voltage Dependent Resistors, supplied by N. V. Philips, have been placed.

We thank Dr. C. J. Zilverschoon for the courtesy of permitting us the republication of the figures 3 and 4 from his thesis. Also some of the work described in this article was done in combination with him.

This work is part of the research of the "Stichting voor Fundamenteel Onderzoek der Materie" and is made possible by financial support from the "Nederlandse Organisatie voor Zuiver Wetenschappelijk Onderzoek". 